\title{
Neoisoptera repetitively colonised Madagascar after the Middle Miocene climatic optimum
}

Menglin Wang ${ }^{1}$, Simon Hellemans ${ }^{1}$, Aleš Buček ${ }^{1}$, Taisuke Kanao ${ }^{1,2}$, Jigyasa Arora ${ }^{1}$, Crystal Clitheroe $^{1}$, Jean-Jacques Rafanomezantsoa ${ }^{3}$, Brian L. Fisher ${ }^{3,4}$, Rudolf Scheffrahn ${ }^{5}$, David Sillam-Dussès ${ }^{6,7}$, Yves Roisin $^{8}$, Jan Šobotník ${ }^{7}$, Thomas Bourguignon ${ }^{1,7}$

${ }^{1}$ Okinawa Institute of Science \& Technology Graduate University, 1919-1 Tancha, Onna-son, Okinawa, 904-0495, Japan

${ }^{2}$ Faculty of Science, Yamagata University, Yamagata, Japan

${ }^{3}$ Madagascar Biodiversity Center, Parc Botanique et Zoologique de Tsimbazaza,

Antananarivo 101, Madagascar

${ }^{4}$ California Academy of Sciences, San Francisco, CA, USA

${ }^{5}$ Fort Lauderdale Research and Education Center, Institute for Food and Agricultural

Sciences, 3205 College Avenue, Davie, Florida 33314 USA

${ }^{6}$ Laboratory of Experimental and Comparative Ethology, UR 4443, University Sorbonne Paris Nord, Villetaneuse, France

${ }^{7}$ Faculty of Tropical AgriSciences, Czech University of Life Sciences, Prague, Czech Republic ${ }^{8}$ Evolutionary Biology and Ecology, Université Libre de Bruxelles, Brussels, Belgium

Authors for correspondence: Menglin Wang, email: menglinhsy@outlook.com; Thomas Bourguignon, email: thomas.bourguignon@oist.jp 


\begin{abstract}
Madagascar is home to many endemic plant and animal species owing to its ancient isolation from other landmasses. This unique fauna includes several lineages of termites, a group of insects known for their key role in organic matter decomposition in many terrestrial ecosystems. How and when termites colonised Madagascar remains unknown. In this study, we used 601 mitochondrial genomes, 93 of which were generated from Madagascan samples, to infer the global historical biogeography of Neoisoptera, a lineage containing upwards of $80 \%$ of described termite species. Our results indicate that Neoisoptera colonised Madagascar between seven to ten times independently during the Miocene, between 8.4-16.6 Ma (95\% HPD: 6.1-19.9 Ma). This timing matches that of the colonization of Australia by Neoisoptera. Furthermore, the taxonomic composition of the Neoisopteran fauna of Madagascar and Australia are strikingly similar, with Madagascar harbouring an additional two lineages absent from Australia. Therefore, akin to Australia, Neoisoptera colonised Madagascar during the global expansion of grasslands, possibly helped by the ecological opportunities arising from the spread of this new biome.
\end{abstract}

Keywords: Australia; endemism; historical biogeography; over-water dispersal; vicariance 


\section{Introduction}

Madagascar is the world's fourth largest island and is home to a great many endemic plant and animal species $[1,2]$. One important reason for the peculiarity of its biota is its ancient isolation from other landmasses [2]. Madagascar, together with India, broke away from Africa 160 million years ago (Ma) and has retained a distance of $\sim 400 \mathrm{~km}$ from East Africa coast for the last 120 million years [3,4]. India subsequently broke away from Madagascar and started drifting northward, leaving Madagascar separated from other continental landmasses for the last 88 Ma [5]. This long isolation is the source of Madagascar's unique biota.

The fauna of Madagascar has either been interpreted as resulting from vicariance or dispersal origin. Early biogeographers, unaware of the motion of continental landmasses, explained the origin of Madagascar fauna by long-distance over-water dispersals (e.g., Matthew 1915, Simpson 1940) [6,7]. Subsequently, the validation of the continental drift hypothesis [8] in the 1960s initiated a paradigm shift, and vicariance became widely accepted as the dominant mechanism responsible for the Madagascar unique fauna $[9,10]$. However, the time-calibrated phylogenies produced during the last two decades have revealed that the majority of animal lineages found in Madagascar are younger than the split of Madagascar from continental Africa and India (e.g., Crottini et al. 2012) [11]. This timing implies that Madagascar predominantly acquired its fauna by means of long-distance over-water dispersals after its separation from other landmasses [12]. For instance, the distributions of the extinct elephant bird [13] and the iconic chameleons [14] are explained by such dispersals. Long-distance over-water dispersals also explain the distribution of several Malagasy insect lineages, such as the millipede assassin bugs [15], the beetle tribe Scarabaeini [16], and the hissing cockroaches [17]. Only a few insect lineages, such as the Malagasy alderfly genus Haplosialis [18], the cascade beetles [19], and the whirligig beetles [20] are ancient enough to have their modern distribution potentially resulting from vicariance.

Termites are a group of social cockroaches feeding on lignocellulose at various stages of decomposition, from hard wood to the organic matter present in the soil [21]. They include 3000 described species mostly distributed across the tropical and subtropical regions $[22,23]$. The oldest known fossils of termites are 130 million years old (Myo) and date back 
from the early Cretaceous [24,25]. Time-calibrated phylogenies provide slightly older age estimates and suggest that the last common ancestor of modern termites roamed the Earth 140-150 Ma [25-29]. The origin of termites therefore predates the breakup of Gondwana, indicating vicariance may explain the current distribution of early-diverging termite lineages. However, the termite fauna of Madagascar is known to comprise derived genera of Kalotermitidae and Neoisoptera [30-36] and appears to lack early-diverging termite lineages, such as Stolotermitidae and Archotermopsidae, whose distribution may bear the signature of vicariance. Madagascar therefore acquired its modern termite fauna by means of long-distance over-water dispersals, presumably via rafting in floating wood pieces or vegetative rafts that contained parts of termite colonies [37].

The pathways and timing of the spread of termites across continents have been studied in detail in Neoisoptera [38-41]. However, the historical biogeography of Neoisoptera in Madagascar has been largely overlooked. Neoisoptera is composed of four families, Stylotermitidae, Rhinotermitidae, Serritermitidae, and Termitidae, and contains upwards of $80 \%$ of described termite species $[23,26]$. The Neoisoptera are represented in Madagascar by a handful of endemic genera and by a few genera also found in continental Africa and in the Oriental region $[30,31,33,35]$. The only Malagasy termite lineage whose historical biogeography has been studied in detail is the fungus-growing termite genus Microtermes, which colonised Madagascar from continental Africa via a single long-distance over-water dispersal 13 Ma $[42,43]$. This dispersal event was presumably facilitated by the acquisition of a vertical mode of transmission of Termitomyces fungal symbionts in Microtermes [44]. The timing and geographic origin of other dispersal events, so well as the number of these dispersal events, are presently unknown and require further investigations.

In this study, we reconstructed robust time-calibrated phylogenetic trees of termites using the mitochondrial genomes of 586 Neoisoptera (including 93 Madagascan samples) and 14 outgroups. Our dataset is representative of the worldwide distribution of Neoisoptera and includes species from the Afrotropical, Australian, Madagascan, Nearctic, Neotropical (including Panamanian), Oriental (including Sino-Japanese), Palaearctic, Saharo-Arabian, and Oceanian realms, as defined by Holt et al. (2013) [45]. We used our time-calibrated phylogenetic trees to shed light on the evolution of Neoisoptera, the main termite lineage found in the Madagascan realm. Our specific aims were (i) to provide the first 
comprehensive phylogenetic tree of Malagasy Neoisoptera; and (ii) to investigate the geographic origin and the timing of dispersal and diversification of the Neoisoptera lineages present in Madagascar.

\section{Material and Methods}

(a) Biological Samples and Mitochondrial Genome Sequencing

We sequenced the mitochondrial genomes of 92 termite samples from Madagascar. We also sequenced an additional 30 mitochondrial genomes from termite samples collected outside Madagascar, including 13 samples from the Afrotropical realm, two samples from the Saharo-Arabian realm, nine Neotropical samples, one Oceanian sample, and five Nearctic samples (Table S1). These 30 samples mostly belonged to termite lineages present in Madagascar and underrepresented in previous studies, such as Amitermes, Psammotermes, and Prorhinotermes. Their inclusion improves our reconstructions of ancestral ranges globally and for the Madagascan realm. We combined the 122 mitochondrial genomes sequenced in this study with 478 termite mitochondrial genomes previously published, including the mitochondrial genome of the Madagascan Prorhinotermes canalifrons from Reunion Island [27,39-41,46-48]. We also obtained the mitochondrial genome of the cockroach Cryptocercus relictus [47], a representative of Cryptocercidae, the sister group of termites. Specimens were tentatively identified based on available taxonomic works and similarity to publicly available COII sequences $[23,30,31,36,49,50]$.

We extracted DNA from two or three individuals preserved in RNA-later ${ }^{\circledR}$ or in $80 \%$ ethanol. Samples preserved in RNA-later ${ }^{\circledR}$ were stored at $-20^{\circ} \mathrm{C}$ or $-80^{\circ} \mathrm{C}$ until DNA extraction. Samples preserved in $80 \%$ ethanol were stored at room temperature for upwards of 20 years. We used one of the following three sequencing strategies: (i) long-range PCR followed by high-throughput DNA sequencing for samples stored in RNA-later $®$; (ii) wholegenome shotgun sequencing for samples stored in RNA-later ${ }^{\circledR}$; and (iii) whole-genome shotgun sequencing for samples stored in $80 \%$ ethanol. In all three cases, DNA was extracted with the DNeasy Blood \& Tissue extraction kit (Qiagen); and libraries were prepared using the NEBNext ${ }^{\circledR}$ Ultra ${ }^{\text {TM }}$ II FS DNA Library Preparation Kit (New England 
Biolabs) and the Unique Dual Indexing Kit (New England Biolabs). Libraries were prepared with one-fifteenth of the reagent volumes recommended by the manufacturer.

For the (i) first strategy, DNA was extracted using specimens from which the digestive tract was removed. The whole mitochondrial genomes were amplified in two long-range PCR reactions using the TaKaRa LA Taq polymerase and the primer sets and PCR conditions previously described in Bourguignon et al. (2016)[41]. We mixed both amplicons in equimolar concentration and prepared one library for each sample separately. Libraries were pooled in equimolar concentration and paired-end sequenced using the Illumina Miseq2000 platform. For the (ii) second strategy, whole genomic DNA was extracted from whole body of termite workers including guts. Libraries were pooled in equimolar concentration and paired-end sequenced using the Illumina Hiseq2500 or Hiseq4000 platforms. For the (iii) third strategy, whole genomic DNA was extracted from whole body of termite workers including gut. Libraries were prepared without enzymatic fragmentation step. Libraries were pooled in equimolar concentration and paired-end sequenced using the Illumina HiSeq $X$ or Novaseq platforms.

\section{(b) Assembly and Alignment}

Raw reads were quality-checked with Fastp v0.20.1 [51]. Read adaptors were trimmed. Filtered reads were assembled using metaSPAdes v3.13.0 [52], and retrieved and annotated with MitoFinder v1.4 [53]. IMRA was used as an attempt to elongate mitochondrial genomes that were not assembled in one contig [54]. The control regions were omitted because they present repetitive patterns difficult to assemble with short reads.

All genes were aligned separately. The 22 transfer RNA genes and the two ribosomal RNA genes were aligned as DNA sequences with MAFFT v7.305 [55]. The 13 protein-coding genes were translated into amino acid sequences using EMBOSS v6.6.0 [56]and aligned using MAFFT. Amino acid sequence alignments were back-translated into DNA sequences using Pal2Nal [57]. The 37 gene alignments were concatenated with FASconCAT-G_v1.04.pl [58].

(c) Phylogenetic Analyses 
The concatenated sequence alignment was partitioned into five subsets: one for the combined transfer RNA genes, one for the combined ribosomal RNA genes, and one for each codon position of the protein-coding genes. The phylogenetic analyses were performed with and without third codon positions. Phylogenetic relationships were inferred using maximum likelihood and Bayesian inference methods. We used IQ-TREE v1.6.12 [59] to reconstruct maximum likelihood phylogenetic trees. The best-fit nucleotide substitution model was determined with the Bayesian Information Criterion using ModelFinder [60] implemented in IQ-TREE. Branch supports were estimated using 1000 bootstrap replicates [61]. Bayesian analyses were implemented in MrBayes v3.2.3 using a GTR+G model of nucleotide substitution [62]. The tree and the posterior distribution of parameters were estimated from MCMC samplings. Each analysis was run with four chains, three hot and one cold. Each analysis was run in four replicates to ensure the convergence of the chains. For the analyses with third codon positions included, the chains were run for 40 million generations with a $25 \%$ burn-in fraction. For the analyses without third codon positions, the chains were run for 20 million generations with burn-in fraction set to $10 \%$. All the chains were sampled every 5,000 generations. The mixing of the chains and the behaviour of all parameters were examined in Tracer v1.7.1 [63]. For all analyses, the topology was constrained to harbour a sister relationship between the subfamilies Sphaerotermitinae and Macrotermitinae, as supported by transcriptome-based phylogenies [28].

\section{(d) Divergence time estimation}

We analysed the concatenated sequence alignments with and without third codon positions and reconstructed time-calibrated phylogenetic trees using BEAST v2.6.2 [64]. Each analysis was run twice to ensure the convergence of the chain. The rate variation across branches was modelled using an uncorrelated lognormal relaxed clock. We used the Yule model for the tree prior. $A$ GTR $+G$ model of nucleotide substitution was assigned to each partition. For

the analyses without third codon positions, we sampled the tree and parameter values of the chain every 50,000 steps over a total of 350 million generations. The first $10 \%$ of generations were discarded as burn-in. For the analyses with third codon positions included, the chain was run over 600 million generations and the first $20 \%$ sampled trees were 
discarded. The mixing of the chains and the behaviour of all parameters were examined with Tracer v1.7.1 [63].

The molecular clock was calibrated using 14 fossils as minimum age constraints (Table S2). We used the youngest possible age for each fossil as reported in the Fossilworks database [65] (last accessed on January 2021, 31 ${ }^{\text {st }}$. We used the criteria described by Parham et al. (2012) to select fossils. For each fossil calibration, we also determined a soft maximum bound using the phylogenetic bracketing approach [66,67]. Each calibration was implemented as exponential priors on node time. We previously justified the use of every fossil calibration used in this study [28]. We used TreeAnnotator to generate a maximum clade credibility consensus tree.

(e) Biogeographic analyses

We reconstructed the historical biogeography of Neoisoptera using the $\mathrm{R}$ package BioGeoBEARS [68]. The Madagascan realm includes Madagascar and neighbouring islands: Comoros, Mascarenes, and Seychelles. We used sampling locations to assign each tip to a biogeographic realm. A total of six phylogenetic reconstructions, estimated with IQ-TREE, MrBayes, and BEAST2 (with and without third codon positions), were subjected to ancestral range reconstructions with BioGeoBEARS. For each phylogenetic tree, we carried out ancestral range reconstructions with the DEC model (Dispersal-Extinction-Cladogenesis), the DIVALIKE model (Dispersal-Vicariance Analysis), and the BAYAREALIKE model. We run each model with and without the parameter " $j$ " allowing jump dispersals, which correspond to speciation events following long-distance dispersals [69]. The best-fit model was determined for each phylogenetic reconstruction using AICC (Akaike Information Criterion with sample size corrected).

\section{Results}

(a) Topology of the phylogenetic trees

Our six phylogenetic trees were largely congruent with respect to interfamily and intergeneric relationships, with the exception of a few nodes with low posterior 
probabilities and bootstrap supports (Figures 1, S1-6). They showed that the Neoisoptera were represented by species belonging to ten lineages of Rhinotermitidae and Termitidae in the Madagascan realm (Figures 1, S1-S6). The Rhinotermitidae were represented by three species: Prorhinotermes canalifrons, Coptotermes truncatus, and Psammotermes voeltzkowi. All three species belonged to genera also present in other biogeographic realms. The seven remaining lineages were part of the Termitidae and formed clades endemic to the Madagascan realm, including one clade of Macrotermitinae, two clades of Nasutitermitinae, and four clades of Termitinae. The only Madagascan clade of Macrotermitinae included several species of Microtermes that formed the sister group of a clade composed of African Microtermes and the Oriental Ancistrotermes pakistanicus. One of the two Madagascan clades of Nasutitermitinae contained Malagasitermes milloti, Coarctotermes, and several species assigned to the polyphyletic Nasutitermes. The sister group of this clade varied among analyses. The other Madagascan clade of Nasutitermitinae only included Nasutitermes sp. 1, retrieved as sister to a group of Oriental species. The four Madagascan clades of Termitinae belonged to Microcerotermes, Amitermes, and the Termes group, which contained two Madagascan clades. The Madagascan Microcerotermes included upwards of nine species with an unresolved sister group. Amitermes was represented by two species forming the sister group of a lineage including African, Saharo-Arabian, Oriental, and Australian Amitermes. One of the two Madagascan clades of the Termes group included Quasitermes, Capritermes, and a species resembling Quasitermes. This first clade was sister to a clade containing the Malagasy and Oriental species of Termes as well as the Australian members of the Termes group.

\section{(b) Divergence times}

The time-calibrated phylogenetic trees reconstructed with and without third codon positions of protein-coding genes diverged in their age estimates by up to 5 million years (Figures 1, S1-2). The divergences were smaller than 2.2 million years for the nodes representing the splits between Madagascan clades and their sister groups (Figures 1, S1-2). Given the similar divergence age estimates obtained with both analyses, we will only discuss the results of the analysis with third codon positions excluded for the sake of simplicity. 
All Madagascan clades of Neoisoptera diverged from their sister groups during the Miocene (Figure 2). Within the Rhinotermitidae, the Madagascan Prorhinotermes, Psammotermes, and Coptotermes diverged from their sister groups $9.0 \mathrm{Ma}(95 \%$ height posterior density (HPD): 6.0-12.1 Ma), 9.0 Ma (95\% HPD: 5.0-13.2 Ma), and 8.4 Ma (95\% HPD: 6.1-10.8 Ma), respectively. Within the Termitidae, the Madagascan macrotermitine Microtermes diverged from their sister group 16.6 Ma (95\% HPD: 13.4-19.9 Ma). The Madagascan nasutitermitine clade containing Malagasitermes milloti and Coarctotermes diverged from its sister $14.4 \mathrm{Ma}$ (95\% HPD: 12.3-16.5 Ma). The other Madagascan nasutitermitine clade, composed of Nasutitermes sp. 1, diverged from its Oriental sister group 10.7 Ma (95\% HPD: 8.2-13.2 Ma). Within the termitines, we dated the divergence between the Madagascan Amitermes and other Amitermes species at 13.1 Ma (95\% HPD: 11.3-15.1 Ma). The most recent common ancestor of all Madagascan Microcerotermes and their sister group was estimated at 14.8 Ma (95\% HPD: 12.5-17.2 Ma). The Madagascan Quasitermes + Capritermes clade diverged from its sister group 14.0 Ma (95\% HPD: 11.6-16.5 Ma), while the Madagascan Termes sp. B diverged from its sister group 11.7 Ma (95\% HPD: 9.5-13.9 Ma).

\section{(c) Biogeographic reconstruction}

We reconstructed the ancestral range distribution of Neoisoptera on our six phylogenetic trees using six different models. The DEC $+j$ model was the best-fit model for all trees, except for the BI tree without third positions for which the best-fit model was the DIVALIKE $+j$ model (for details, see Table S3). The models with the parameter $+j$ fit the data better than the models without this parameter, indicating that jump dispersals played a major role in the biogeographic history of Neoisoptera.

Our analyses indicated that the Madagascan realm was colonised by seven to ten longdistance over-water dispersals (Figure 2). Four Neoisopteran lineages unambiguously colonised the Madagascan realm once: Coptotermes truncatus colonised the Madagascan realm from the Oriental realm; Microtermes from the Afrotropical realm; and Microcerotermes and Amitermes from an unidentified realm. The colonization of the Madagascan realm by Prorhinotermes + Psammotermes, the Nasutitermitinae, and the Termes group involved one or two long-distance over-water dispersals. Following the most likely scenario, Prorhinotermes and Psammotermes independently colonised the 
Madagascan realm through long-distance over-water dispersals from undetermined biogeographic realms. The alternative scenario of an early arrival of the common ancestor of Prorhinotermes and Psammotermes, followed by subsequent long-distance over-water dispersals to other biogeographic realms, was less likely but could not be excluded. Similarly, the two Madagascan clades of Nasutitermitinae probably originated from two independent dispersals from Africa to the Madagascan realm. A less likely alternative featured one longdistance over-water dispersal from Africa to the Madagascan realm followed by two dispersal events from Madagascar to the Afrotropical and Oriental realms. Lastly, the Madagascan realm was either colonised once by the Termes group followed by one or several dispersal events out of the Madagascan realm, or it was independently colonised twice, once by each Malagasy lineage of the Termes group.

\section{Discussion}

(a) Long-distance over-water dispersals of Neoisoptera to and from the Madagascan realm: taxonomic identity, timing, and origin of the dispersers

We reconstructed the most comprehensive phylogenetic tree of Neoisoptera to date. The relationships among the main lineages of Neoisoptera were largely congruent with earlier molecular studies based on mitochondrial genome and transcriptome data $[27,28,40]$. Our time estimates were generally younger than those found by these studies, but remained congruent, with overlapping HPD intervals. These differences may pertain to the use of different fossil calibrations and/or to the changes of fossil age estimations at the time of publication of these studies. For example, we previously used the 110 Myo Cratokalotermes santanensis [70] to calibrate Kalotermitidae + Neoisoptera $[27,40]$ while we now use the 95 Myo Archeorhinotermes rossi [71] to calibrate the same node.

Before this study, three genera of Rhinotermitidae - Coptotermes, Prorhinotermes, and Psammotermes - and four groups of Termitidae —Microtermes, Microcerotermes, the Nasutitermitinae, and the Termes group - were known to be represented by species native to the Madagascan realm[23,30,31,33,35,72]. We sequenced upward of 40 Malagasy species, while Eggleton and Davies (2003) listed 33 species of Neoisoptera described from Madagascar, implying the existence of several new species among our samples [72]. The 
most notable species were two new species of Amitermes, a genus previously unknown from the Madagascan realm. We also found that the Malagasy species of Nasutitermitinae and of the Termes group do not form monophyletic groups. Therefore, the Madagascan termite fauna is more phylogenetically diverse than previously envisioned.

Our ancestral state reconstructions indicated that Neoisoptera colonised the Madagascan realm seven to ten times independently and possibly dispersed out of the Madagascan realm up to four times. The dispersal events to and from the Madagascan realm took place 8.4-16.6 Ma (95\% HPD: 6.1-19.9 Ma), between the mid-Miocene climatic optimum [73] and the end of the Miocene. Therefore, our results indicate that the Madagascan realm acquired its fauna of Neoisoptera through long-distance over-water dispersal events.

Our ancestral range reconstructions also revealed one long-distance over-water dispersal event within the Madagascan realm, that of Prorhinotermes canalifrons between Madagascar and the Reunion Island 2.1 Ma (95\% HPD: 1.3-3.0 Ma). This species is also known from Mauritius, Comoros, and Seychelles [23], potentially indicating additional overwater dispersals among islands of the Madagascan realm for this genus with high dispersal abilities and tolerance to salinity [74,75]. Two other species, Coptotermes truncatus and Microcerotermes subtilis, as well as the nasutitermitine genus Kaudernitermes, are also known from Madagascar and several neighbouring islands [23], indicating further dispersals between islands. Whether these dispersals were mediated by human activities or were longdistance over-water dispersals, as was the case for $P$. canalifrons in Madagascar and the Reunion islands, is unclear. Additional sequence data from the termite fauna of the Reunion Island, Mauritius, Comoros, and Seychelles are needed to identify the processes of colonization of these islands.

We were able to identify the source of three dispersal events to the Madagascan realm: Coptotermes truncatus has Oriental origin, Microtermes has African origin [42], and the nasutitermitines arrived from Africa at least once. The origin of other Madagascan lineages remains unresolved. Therefore, our results do not provide a global picture of the origin of the Madagascan Neoisoptera, although we show that some lineages have African and Oriental origins, as is the case for many other taxa $[12,76]$. Our ancestral range reconstructions also point to the possibility that Neoisoptera dispersed out of the Madagascan realm on multiple occasions, although these events remain speculative. 
Additional sequences from other biogeographical realms are required to identify the origin of Madagascan Neoisoptera lineages with yet unresolved origin.

(b) The colonization of the Madagascan and Australian realms by Neoisoptera coincides with the global expansion of grasslands

The colonization of the Madagascan realm by Neoisoptera coincides with the colonization of the Australian realm [39-41,77] (Figure 2). The colonization of both realms was initiated around the Miocene climatic optimum, 15-17 Ma, and continued over the next five to ten million years while the world climate gradually cooled down [73] and grasslands expanded worldwide [78]. It is therefore tempting to attribute this coincidental timing to shared historical climatic and ecological changes in Australia and Madagascar.

The climate of Australia became drier during the Middle Miocene $14 \mathrm{Ma}$, and new biomes composed of flora and fauna adapted to arid conditions expended $[79,80]$. The expansion of the arid-adapted biomes in Australia was accompanied by the opening of new ecological opportunities for local Australian taxa and for colonisers arriving from other continents [79], which included a dozen of lineages of Neoisoptera [39-41,77] (Figure 2) . Unlike in Australia, the origin of grasslands in Madagascar is still debated. Human activities have undoubtedly contributed to the expansion of modern Madagascar's grasslands, and some authors have argued that, prior to human arrival, the areas presently covered by grasslands were forested and only contained patches of grasslands $[81,82]$. The alternative view is that Madagascar's grassland first appeared during the Miocene and gradually expanded, an expansion that was accelerated by human arrival [83-85]. Whichever scenario turns out to be correct, the arrival of Neoisoptera in the Madagascan realm was concurrent to the diversification of grasses in Madagascar, whose number of species exponentially increased since around 20 Ma [86]. The divergence between the two grass-feeding species Coarctotermes pauliani and Coarctotermes baharaensis 6.5 Ma (95\% HPD: 4.2-8.8 Ma) indicates an early adaptation of some termite species to grassland in Madagascar. However, the bulk of the termite diversity in Madagascar is associated with forested areas [72]. The colonization of Madagascar and Australia by Neoisoptera therefore coincides with the global spread of grasses. 
In addition to the timing of colonization, another parallel that can be made between the Neoisopteran fauna of the Madagascan and Australian realms is the similarity of their taxonomic composition. The Madagascan realm was colonised by two genera not found in Australia, the rhinotermitid Psammotermes and the termitid Microtermes [30], while the Australian realm was colonised by three genera absent from Madagascar, the rhinotermitids Schedorhinotermes, Parrhinotermes, and Heterotermes [87]. Note that Heterotermes philippinensis was introduced in Madagascar and in Mauritius [88,89]. In contrast, both realms were colonised by the rhinotermitid genera Coptotermes and Prorhinotermes and by the termitid genera Microcerotermes, Amitermes, Termes, and Nasutitermes [30,87]. Of note, the latter three genera are paraphyletic and include a number of genera endemic to the Madagascan and Australian realms nested within them. Therefore, these two realms host taxonomically similar communities of Neoisoptera, acquired within the same geological time interval. These observations suggest the existence of ecological preadaptations in the Neoisopteran lineages that colonised Madagascar and Australia, two distant landmasses presently dominated by grasslands and savannah biomes.

We previously reconstructed the global spread of Neoisoptera without samples from Madagascar [38-41]. The sequencing of 92 termite samples from Madagascar provides an opportunity to refine the picture of the global spread of Neoisoptera. The higher termites, which make up over $80 \%$ of species of Neoisoptera [23], originated from Africa and dispersed worldwide in two phases [40]. During the first phase, which spanned the Oligocene and the early Miocene, 34-20 Ma, higher termites colonised the Neotropical and Oriental realms via a dozen of over-water dispersal events [40]. Our results show that the second phase, which took place during the Miocene, 20-8 Ma, was characterised by the colonization of Australia and Madagascar by higher termites and coincides with the global expansion of grasslands.

\section{Acknowledgments}

We thank the DNA Sequencing Section and the Scientific Computation and Data Analysis Section (SCDA) of the Okinawa Institute of Science and Technology Graduate University, Okinawa, Japan, for assistance with sequencing and for providing access to the OIST computing cluster, respectively. This work was supported by the subsidiary funding to OIST, 
by the Czech Science Foundation (project No. 15-07015Y), by the Internal Grant Agency of the Faculty of Tropical AgriSciences, CULS (20213112), by the Japan Society for the Promotion of Science through a DC2 graduate student fellowship to JA and a postdoctoral fellowship to SH (19F19819).

\section{References}

1. Buerki S, Devey DS, Callmander MW, Phillipson PB, Forest F. 2013 Spatio-temporal history of the endemic genera of Madagascar. Bot. J. Linn. Soc. 171, 304-329. (doi:10.1111/boj.12008)

2. Goodman SM, Benstead JP. 2005 Updated estimates of biotic diversity and endemism for Madagascar. Oryx 39, 73-77. (doi:10.1017/S0030605305000128)

3. Ali JR, Aitchison JC. 2008 Gondwana to Asia: plate tectonics, paleogeography and the biological connectivity of the Indian sub-continent from the Middle Jurassic through latest Eocene (166-35 Ma). Earth-Science Rev. 88, 145-166. (doi:10.1016/j.earscirev.2008.01.007)

4. Seward D, Grujic D, Schreurs G. 2004 An insight into the breakup of Gondwana: identifying events through low-temperature thermochronology from the basement rocks of Madagascar. Tectonics 23, TC3007. (doi:10.1029/2003TC001556)

5. Storey M, Mahoney JJ, Saunders AD, Duncan RA, Kelley SP, Coffin MF. 1995 Timing of hot spot-related volcanism and the breakup of Madagascar and India. Science 267, 852-855. (doi:10.1126/science.267.5199.852)

6. Simpson GG. 1940 Antarctica as a faunal migration route. Proc. Sixth Pacific Sci. Congr. Pacific Sci. Assoc. (Berkeley Los Angeles Univ. Calif. Press. 2, 755-768.

7. Matthew WD. 1915 Climate and evolution. Ann. N. Y. Acad. Sci. 24, 171-318. (doi:10.1111/j.1749-6632.1914.tb55346.x)

8. Wegener A. 1912 Die Entstehung der Kontinente. Geol. Rundschau 3, 276-292. (doi:10.1007/BF02202896)

9. Noonan BP, Chippindale PT. 2006 Vicariant origin of Malagasy reptiles supports late cretaceous antarctic land bridge. Am. Nat. 168, 730-741. (doi:10.1086/509052)

10. Bossuyt F, Brown RM, Hillis DM, Cannatella DC, Milinkovitch MC. 2006 Phylogeny and biogeography of a cosmopolitan frog radiation: late cretaceous diversification resulted in continent-scale endemism in the family Ranidae. Syst. Biol. 55, 579-594. (doi:10.1080/10635150600812551)

11. Crottini A, Madsen O, Poux C, Strauß A, Vieites DR, Vences M. 2012 Vertebrate timetree elucidates the biogeographic pattern of a major biotic change around the K-T boundary in Madagascar. Proc. Natl. Acad. Sci. U. S. A. 109, 5358-5363. (doi:10.1073/pnas.1112487109)

12. Yoder AD, Nowak MD. 2006 Has vicariance or dispersal been the predominant biogeographic force in Madagascar? Only time will tell. Annu. Rev. Ecol. Evol. Syst. 37, 
405-431. (doi:10.1146/annurev.ecolsys.37.091305.110239)

13. Mitchell KJ, Llamas B, Soubrier J, Rawlence NJ, Worthy TH, Wood J, Lee MSY, Cooper A. 2014 Ancient DNA reveals elephant birds and kiwi are sister taxa and clarifies ratite bird evolution. Science 344, 898-900. (doi:10.1126/science.1251981)

14. Raxworthy CJ, Forstner MRJ, Nussbaum RA. 2002 Chameleon radiation by oceanic dispersal. Nature 415, 784-787. (doi:10.1038/415784a)

15. Forthman M, Weirauch C. 2016 Phylogenetics and biogeography of the endemic Madagascan millipede assassin bugs (Hemiptera: Reduviidae: Ectrichodiinae). Mol. Phylogenet. Evol. 100, 219-233. (doi:10.1016/j.ympev.2016.03.011)

16. Sole CL, Wirta H, Forgie SA, Scholtz CH. 2011 Origin of Madagascan Scarabaeini dung beetles (Coleoptera: Scarabaeidae): dispersal from Africa. Insect Syst. Evol. 42, 29-40. (doi:10.1163/187631211X552800)

17. Bourguignon T et al. 2018 Transoceanic dispersal and plate tectonics shaped global cockroach distributions: evidence from mitochondrial phylogenomics. Mol. Biol. Evol. 35, 970-983. (doi:10.1093/molbev/msy013)

18. Liu X, Hayashi F, Yang D. 2015 Phylogeny of the family Sialidae (Insecta: Megaloptera) inferred from morphological data, with implications for generic classification and historical biogeography. Cladistics 31, 18-49. (doi:10.1111/cla.12071)

19. Toussaint EFA, Fikáček M, Short AEZ. 2016 India-Madagascar vicariance explains cascade beetle biogeography. Biol. J. Linn. Soc. 118, 982-991. (doi:10.1111/bij.12791)

20. Gustafson GT, Prokin AA, Bukontaite R, Bergsten J, Miller KB. 2017 Tip-dated phylogeny of whirligig beetles reveals ancient lineage surviving on Madagascar. Sci. Rep. 7, 1-9. (doi:10.1038/s41598-017-08403-1)

21. Donovan SE, Jones DT, Sands WA, Eggleton P. 2000 Morphological phylogenetics of termites (Isoptera). Biol. J. Linn. Soc. 70, 467-513. (doi:10.1006/bijl.1999.0428)

22. Eggleton P. 2000 Global Patterns of Termite Diversity. In: Abe T., Bignell D.E., Higashi M. (eds) Termites: Evolution, Sociality, Symbioses, Ecology. pp. 25-51. Dordrecht: Springer Netherlands. (doi:10.1007/978-94-017-3223-9_2)

23. Krishna K, Grimaldi DA, Krishna V, Engel MS. 2013 Treatise on the Isoptera of the world. Bull. Am. Museum Nat. Hist. 377, 1-200. (doi:10.1206/377.6)

24. Thorne B, Grimaldi D, Krishna K. 2000 Early fossil history of termites. In Termites: evolution, sociality, symbioses, ecology (ed HM Abe T, Bignell DE), pp. 77-93. Dordrecht (The Netherlands): Kluwer Academic Publishers.

25. Engel MS, Barden P, Riccio ML, Grimaldi DA. 2016 Morphologically specialized termite castes and advanced sociality in the early Cretaceous. Curr. Biol. 26, 522-530. (doi:10.1016/j.cub.2015.12.061)

26. Engel MS, Grimaldi DA, Krishna K. 2009 Termites (Isoptera): their phylogeny, classification, and rise to ecological dominance. Am. Museum Novit. 2009, 1-27. (doi:10.1206/651.1)

27. Bourguignon T et al. 2015 The evolutionary history of termites as inferred from 66 mitochondrial genomes. Mol. Biol. Evol. 32, 406-421. (doi:10.1093/molbev/msu308) 
28. Bucek A, Šobotník J, He S, Shi M, McMahon DP, Holmes EC, Roisin Y, Lo N, Bourguignon T. 2019 Evolution of termite symbiosis informed by transcriptome-based phylogenies. Curr. Biol. 29, 3728-3734.e4. (doi:10.1016/j.cub.2019.08.076)

29. Legendre F, Nel A, Svenson GJ, Robillard T, Pellens R, Grandcolas P. 2015 Phylogeny of Dictyoptera: dating the origin of cockroaches, praying mantises and termites with molecular data and controlled fossil evidence. PLoS One 10, e0130127.

(doi:10.1371/journal.pone.0130127)

30. Cachan P. 1949 Les Termites de Madagascar. Mémoires de l'Institut Scientifique de Madagascar (A) 3 (2). , 177-275.

31. Cachan P. 1951 Les termites de Madagascar. Premier supplément. Mem. L'Institut Sci. Madagascar 5, 1-18.

32. Eggleton P, Davies R. 2003 Isoptera, Termites. in Goodman S. M. and Benstead J . P.(eds) The Natural History of Madagascar. pp. 654-660. University of Chicago Press, Chicago and London.

33. Emerson AE. 1960 Six new genera of Termitinae from the Belgian Congo (Isoptera, Termitidae). Am. Museum Novit. 1988, 1-49.

34. Paulian R. 1970 The termites of Madagascar. In: Biology of Termites, Vol. 2 (K. Krishna \& F. M. Weesner, eds), pp. 281-294. Academic Press, New York.

35. Sjöstedt Y. 1926 Revision der Termiten Afrikas. 3. Monographie. K. Sven. VetenskapsAkademiens Handl. 3, 1-419 + 16 pls.

36. Monaghan MT et al. 2009 Accelerated species inventory on Madagascar using coalescent-based models of species delineation. Syst. Biol. 58, 298-311. (doi:10.1093/sysbio/syp027)

37. Thiel M, Haye P. 2006 The ecology of rafting in the marine environment. iii. Biogeographical and evolutionary consequences. In Oceanography and Marine Biology, pp. 323-429. Taylor and Francis Ltd. (doi:10.1201/9781420006391.ch7)

38. Romero Arias J, Boom A, Wang M, Clitheroe C, Šobotník J, Stiblik P, Bourguignon T, Roisin Y. 2021 Molecular phylogeny and historical biogeography of Apicotermitinae (Blattodea: Termitidae). Syst. Entomol. 46, 741-756. (doi:10.1111/syen.12486)

39. Wang M, Buček A, Šobotník J, Sillam-Dussès D, Evans TA, Roisin Y, Lo N, Bourguignon T. 2019 Historical biogeography of the termite clade Rhinotermitinae (Blattodea: Isoptera). Mol. Phylogenet. Evol. 132, 100-104. (doi:10.1016/j.ympev.2018.11.005)

40. Bourguignon T et al. 2017 Mitochondrial phylogenomics resolves the global spread of higher termites, ecosystem engineers of the tropics. Mol. Biol. Evol. 34, 589-597. (doi:10.1093/molbev/msw253)

41. Bourguignon T, Lo N, Šobotník J, Sillam-Dussès D, Roisin Y, Evans TA. 2016 Oceanic dispersal, vicariance and human introduction shaped the modern distribution of the termites Reticulitermes, Heterotermes and Coptotermes. Proc. R. Soc. B 283, 20160179. (doi:10.1098/rspb.2016.0179)

42. Aanen DK, Eggleton P. 2005 Fungus-growing termites originated in African rain forest. Curr. Biol. 15, 851-855. (doi:10.1016/j.cub.2005.03.043) 
43. Nobre T, Aanen DK. 2010 Dispersion and colonization by fungus-growing termites: Vertical transmission of the symbiont helps, but then...? Commun. Integr. Biol. 3, 248-250. (doi:10.4161/cib.3.3.11415)

44. Nobre T, Eggleton P, Aanen DK. 2010 Vertical transmission as the key to the colonization of Madagascar by fungus-growing termites? Proc. R. Soc. B 277, 359-365. (doi:10.1098/rspb.2009.1373)

45. Holt BG et al. 2013 An update of Wallace's zoogeographic regions of the world. Science 339, 74-78. (doi:10.1126/science.1228282)

46. Cameron SL, Whiting MF. 2007 Mitochondrial genomic comparisons of the subterranean termites from the genus Reticulitermes (Insecta: Isoptera: Rhinotermitidae). Genome 50, 188-202. (doi:10.1139/g06-148)

47. Cameron SL, Lo N, Bourguignon T, Svenson GJ, Evans TA. 2012 A mitochondrial genome phylogeny of termites (Blattodea: Termitoidae): robust support for interfamilial relationships and molecular synapomorphies define major clades. $\mathrm{Mol}$. Phylogenet. Evol. 65, 163-173. (doi:10.1016/J.YMPEV.2012.05.034)

48. Tokuda G, Isagawa H, Sugio K. 2011 The complete mitogenome of the Formosan termite, Coptotermes formosanus Shiraki. Insectes Soc. 59, 17-24. (doi:10.1007/s00040-011-0182-x)

49. Inward DJG, Vogler AP, Eggleton P. 2007 A comprehensive phylogenetic analysis of termites (Isoptera) illuminates key aspects of their evolutionary biology. Mol. Phylogenet. Evol. 44, 953-967. (doi:10.1016/J.YMPEV.2007.05.014)

50. Sands WA. 1992 The termite genus Amitermes in Africa and the Middle East. Nat. Resour. Inst. Bull. 51, 1-140.

51. Chen S, Zhou Y, Chen Y, Gu J. 2018 Fastp: an ultra-fast all-in-one FASTQ preprocessor. In Bioinformatics, pp. i884-i890. Oxford University Press. (doi:10.1093/bioinformatics/bty560)

52. Nurk S, Meleshko D, Korobeynikov A, Pevzner PA. 2017 MetaSPAdes: a new versatile metagenomic assembler. Genome Res. 27, 824-834. (doi:10.1101/gr.213959.116)

53. Allio R, Schomaker-Bastos A, Romiguier J, Prosdocimi F, Nabholz B, Delsuc F. 2020 MitoFinder: efficient automated large-scale extraction of mitogenomic data in target enrichment phylogenomics. Mol. Ecol. Resour. 20, 892-905. (doi:10.1111/17550998.13160)

54. Kinjo Y, Saitoh S, Tokuda G. 2015 An efficient strategy developed for next-generation sequencing of endosymbiont genomes performed using crude DNA isolated from host tissues: a case study of Blattabacterium cuenoti inhabiting the fat bodies of cockroaches. Microbes Environ. 30, 208-220. (doi:10.1264/jsme2.ME14153)

55. Katoh K, Standley DM. 2013 MAFFT multiple sequence alignment software version 7: improvements in performance and usability. Mol. Biol. Evol. 30, 772-780. (doi:10.1093/molbev/mst010)

56. Rice P, Longden I, Bleasby A. 2000 EMBOSS: the European molecular biology open software suite. Trends Genet. 16, 276-277. (doi:10.1016/S0168-9525(00)02024-2) 
57. Suyama M, Torrents D, Bork P. 2006 PAL2NAL: robust conversion of protein sequence alignments into the corresponding codon alignments. Nucleic Acids Res. 34, W609W612. (doi:10.1093/nar/gkl315)

58. Kück P, Longo GC. 2014 FASconCAT-G: extensive functions for multiple sequence alignment preparations concerning phylogenetic studies. Front. Zool. 11, 81. (doi:10.1186/s12983-014-0081-x)

59. Nguyen LT, Schmidt HA, Von Haeseler A, Minh BQ. 2015 IQ-TREE: a fast and effective stochastic algorithm for estimating maximum-likelihood phylogenies. Mol. Biol. Evol. 32, 268-274. (doi:10.1093/molbev/msu300)

60. Kalyaanamoorthy S, Minh BQ, Wong TKF, Von Haeseler A, Jermiin LS. 2017 ModelFinder: fast model selection for accurate phylogenetic estimates. Nat. Methods 14, 587-589. (doi:10.1038/nmeth.4285)

61. Hoang DT, Chernomor O, Von Haeseler A, Minh BQ, Vinh LS. 2018 UFBoot2: improving the ultrafast bootstrap approximation. Mol. Biol. Evol. 35, 518-522. (doi:10.1093/molbev/msx281)

62. Ronquist F et al. 2012 MrBayes 3.2: efficient bayesian phylogenetic Inference and model choice across a large model space. Syst. Biol. 61, 539-542.

(doi:10.1093/sysbio/sys029)

63. Rambaut A, Drummond AJ, Xie D, Baele G, Suchard MA. 2018 Posterior summarization in bayesian phylogenetics using Tracer 1.7. Syst. Biol. 67, 901-904. (doi:10.1093/sysbio/syy032)

64. Bouckaert R, Heled J, Kühnert D, Vaughan T, Wu CH, Xie D, Suchard MA, Rambaut A, Drummond AJ. 2014 BEAST 2: a software platform for bayesian evolutionary analysis. PLoS Comput. Biol. 10, e1003537. (doi:10.1371/journal.pcbi.1003537)

65. Alroy J. 2016 Fossilworks: gateway to the paleobiology database. See http://fossilworks.org.

66. Parham JF et al. 2012 Best practices for justifying fossil calibrations. Syst. Biol. 61, 346-359. (doi:10.1093/sysbio/syr107)

67. Ho SYW, Phillips MJ. 2009 Accounting for calibration uncertainty in phylogenetic estimation of evolutionary divergence times. Syst. Biol. 58, 367-380. (doi:10.1093/sysbio/syp035)

68. Matzke NJ. 2013 Probabilistic historical biogeography: new models for founder-event speciation, imperfect detection, and fossils allow improved accuracy and modeltesting. Front. Biogeogr. 5, 242-248. (doi:10.21425/f5fbg19694)

69. Matzke NJ. 2014 Model selection in historical biogeography reveals that founderevent speciation Is a crucial process in island clades. Syst. Biol. 63, 951-970. (doi:10.1093/SYSBIO/SYU056)

70. Grimaldi DA, Engel MS, Krishna K. 2008 The species of Isoptera (Insecta) from the early Cretaceous Crato formation: a revision. Am. Museum Novit. 3626, 1-30. (doi:10.1206/616.1)

71. Krishna K, Grimaldi DA. 2003 The first Cretaceous Rhinotermitidae (Isoptera): a new 
species, genus, and subfamily in Burmese amber. Am. Museum Novit. 3390, 1-10. (doi:10.1206/0003-0082(2003)390<0001:TFCRIA>2.0.CO;2)

72. Eggleton P, Davies R. 2003 Isoptera,Termites. In The Natural History of Madagascar,,S.M. Goodman, and J.P. Benstead, eds. (Chicago and London: The University of Chicago Press), pp. 654-661. University of Chicago Press, Chicago and London.

73. Zachos J, Pagani H, Sloan L, Thomas E, Billups K. 2001 Trends, rhythms, and aberrations in global climate $65 \mathrm{Ma}$ to present. Science $\mathbf{2 9 2}, 686-693$. (doi:10.1126/science.1059412)

74. Emerson AE. 1955 Geographical origins and dispersions of termite genera. Fieldiana Zool. 37, 465-521. (doi:10.5962/bhl.title.2783)

75. Chiu Cl, Mullins AJ, Kuan KC, Lin M Der, Su NY, Li HF. 2021 Termite salinity tolerance and potential for transoceanic dispersal through rafting. Ecol. Entomol. 46, 106-116. (doi:10.1111/een.12946)

76. Warren BH, Strasberg D, Bruggemann JH, Prys-Jones RP, Thébaud C. 2010 Why does the biota of the Madagascar region have such a strong Asiatic flavour? Cladistics 26, 526-538. (doi:10.1111/j.1096-0031.2009.00300.x)

77. Arab DA, Namyatova A, Evans TA, Cameron SL, Yeates DK, Ho SYW, Lo N. 2017 Parallel evolution of mound-building and grass-feeding in Australian nasute termites. Biol. Lett. 13, 20160665. (doi:10.1098/rsbl.2016.0665)

78. Edwards EJ et al. 2010 The origins of C4 grasslands: integrating evolutionary and ecosystem science. Science 328, 587-591. (doi:10.1126/science.1177216)

79. Crisp MD, Cook LG. 2013 How was the Australian flora assembled over the last 65 million years? A molecular phylogenetic perspective. Annu. Rev. Ecol. Evol. Syst. 44, 303-324. (doi:10.1146/annurev-ecolsys-110512-135910)

80. Martin HA. 2006 Cenozoic climatic change and the development of the arid vegetation in Australia. J. Arid Environ. 66, 533-563.

(doi:10.1016/j.jaridenv.2006.01.009)

81. Crowley BE, Godfrey LR, Hansford JP, Samonds KE. 2021 Seeing the forest for the trees-and the grasses: revisiting the evidence for grazer-maintained grasslands in Madagascar's central highlands. Proc. R. Soc. B 288, 20201785. (doi:10.1098/rspb.2020.1785)

82. Joseph GS, Seymour CL. 2020 Madagascan highlands: originally woodland and forest containing endemic grasses, not grazing-adapted grassland. Proc. R. Soc. B 287, 20201956. (doi:10.1098/rspb.2020.1956)

83. Vorontsova MS et al. 2015 Madagascar's grasses and grasslands: anthropogenic or natural? Proc. R. Soc. B 283, 20152262. (doi:10.1098/rspb.2015.2262)

84. Solofondranohatra CL, Vorontsova MS, Hempson GP, Hackel J, Cable S, Vololoniaina J, Lehmann CER. 2020 Fire and grazing determined grasslands of central Madagascar represent ancient assemblages: grasslands are shaped by disturbance. Proc. R. Soc. $B$ 287, 0598. (doi:10.1098/rspb.2020.0598) 
85. Bond WJ, Silander JA, Ranaivonasy J, Ratsirarson J. 2008 The antiquity of Madagascar's grasslands and the rise of C4 grassy biomes. J. Biogeogr. 35, 1743-1758. (doi:10.1111/j.1365-2699.2008.01923.x)

86. Hackel J, Vorontsova MS, Nanjarisoa OP, Hall RC, Razanatsoa J, Malakasi P, Besnard G. 2018 Grass diversification in Madagascar: in situ radiation of two large C3 shade clades and support for a Miocene to Pliocene origin of C4 grassy biomes. J. Biogeogr. 45, 750-761. (doi:10.1111/jbi.13147)

87. Watson J, Abbey H. 1993 Atlas of Australian Termites. CSIRO Publishing. (doi:10.1071/9780643100657)

88. Cachan P. 1950 Les termites de Madagascar et leurs dégâts. Tananarive-Tsimbazaza, Madagascar: Institut de Recherche Scientifique, 29 pp.

89. Evans TA, Forschler BT, Grace JK. 2013 Biology of invasive termites: a worldwide review. Annu. Rev. Entomol. 58, 455-474. (doi:10.1146/annurev-ento-120811-153554) 
Figure 1. Time-calibrated Bayesian phylogeny inferred from 601 mitochondrial genomes, with the third codon position excluded. Node labels provide a summary of node supports across the six phylogenetic analyses: red stars indicate topology conflicts for at least one analysis; and black diamond indicate support value $<90 \%$ for at least one analysis. Nodes without labels have support values $>90 \%$ for all analyses. Node bars indicate the $95 \%$ HPD intervals estimated with BEAST 2. Tips and node circles are color-coded to indicate biogeographic realms. The colours of node circles indicate ancestral ranges reconstructed with probabilities higher than $65 \%$ for the six phylogenetic trees inferred with IQ-TREE, MrBayes, and BEAST 2, with and without third codon positions. White circles indicate undetermined ancestral distribution. Clades containing species collected in the same biogeographic realm are collapsed, except for species collected in the Madagascan realm. The map shows the biogeographic realms recognised in this study (modified from Holt et al. 2013).

Figure 2. Summary of Madagascar and Australia colonization events. The scenario with 10 dispersal events is displayed. Node bars indicate the 95\% HPD intervals estimated with BEAST 2. The colours of node circles indicate ancestral ranges reconstructed with probabilities higher than $65 \%$ for the six phylogenetic trees inferred with IQ-TREE, MrBayes, and BEAST 2, with and without third codon positions. White circles indicate undetermined ancestral distribution. The map shows the biogeographic realms recognised in this study (modified from Holt et al. 2013). Asterisks indicate ambiguous dispersal events. 
Coptotermes truncatus

Psammotermes voeltzkowi

Prorhinotermes canalifrons

Amitermes

Termes sp. B

Quasitermes + Capritermes

Microcerotermes

Nasutitermes + Coarctotermes + Malagasitermes Nasutitermes sp. 1

Microtermes

Amitermes-group

Coptotermes

Termes-group

Microcerotermes

Heterotermes

Heterotermes

Schedorhinotermes

Nasutitermes

Nasutitermes-group
Pliocene and

Pleistocene

$\begin{array}{lllll}20 & 15 & 10 & 5 & 0\end{array}$

